\begin{tabular}{|c|l|}
\hline Title & Scenarios for the formation of Chasma Boreale, Mars \\
\hline Author(s) & Greve, Ralf \\
\hline Citation & $\begin{array}{l}\text { Icarus, 196/2), 359-367 } \\
\text { https://doi.org/10.1016/.icarus.2007.10.020 }\end{array}$ \\
\hline Issue Date & 2008_08 \\
\hline Doc URL & http://hdl.handle.net/2115/34403 \\
\hline Type & article (author version) \\
\hline File Information & Greve_2008_Icarus.pdf \\
\hline
\end{tabular}

Instructions for use 


\title{
Scenarios for the formation of Chasma Boreale, Mars
}

\author{
RALF Greve \\ Institute of Low Temperature Science, Hokkaido University, \\ Kita-19, Nishi-8, Kita-ku, Sapporo 060-0819, Japan
}

December 20, 2007

Correspondence to: R. Greve (greve@lowtem.hokudai.ac.jp) 


\begin{abstract}
The Martian polar caps feature large chasmata and smaller trough systems which have no counterpart in terrestrial ice sheets. Chasma Boreale cuts about $500 \mathrm{~km}$ into the western part of the north-polar cap, is up to $100 \mathrm{~km}$ wide and up to $2 \mathrm{~km}$ deep. One possible formation mechanism is by a temporary heat source under the ice due to tectonothermal or volcanic activity, which melts the ice from below. It is demonstrated by model simulations that this process is feasible, a moderately increased heat flux of $0.5-1 \mathrm{~W} \mathrm{~m}^{-2}$, sustained over at least tens of thousands of years, producing a topographic depression which resembles the real chasma. Associated meltwater discharge rates are small $\left(<1 \mathrm{~km}^{3} \mathrm{a}^{-1}\right)$, but can exceed $10 \mathrm{~km}^{3} \mathrm{a}^{-1}$ if a stronger heat flux of $10 \mathrm{~W} \mathrm{~m}^{-2}$ is assumed. Local ice-flow velocities during the process of chasma formation can exceed $1 \mathrm{ma}^{-1}$ at the head and scarps of the chasma. However, if the thermal anomaly shuts down, glacial flow quickly decreases, so that the chasma can stay open for an indefinite amount of time without an ongoing, sustaining process under the climate conditions of the most recent millions of years.
\end{abstract}

\title{
1 Introduction
}

The Martian poles are both covered by ice caps. Seasonal caps, which can extend toward the equator until approximately $55^{\circ} \mathrm{N} / \mathrm{S}$, consist of some ten centimeters to meters of $\mathrm{CO}_{2}$ snow which sublimes into the atmosphere during the respective summer season. By contrast, the smaller residual polar caps within approximately $80^{\circ} \mathrm{N} / \mathrm{S}$ are underlain by massive topographic structures, the polar layered deposits. Following the terminology of some recent publications (e.g., Johnson et al. 2000, Byrne and Murray 2002, Greve and Mahajan 2005), the composite systems of the residual caps and the layered deposits shall be referred to as the north- and south-polar cap (NPC/SPC), respectively.

An intriguing feature of the Martian polar caps is the presence of large chasmata and smaller troughs which have no counterpart in terrestrial ice sheets. Chasma Boreale cuts about $500 \mathrm{~km}$ into the western part of the north-polar cap, is up to $100 \mathrm{~km}$ wide, and its scarps are up to $2 \mathrm{~km}$ high (Fig. 1). A similar feature, known as Chasma Australe, exists in the south-polar cap, which is also home to the nearby two-branch system Promethei Chasma and Ultimum Chasma.

In this study, the focus is on Chasma Boreale. A possible explanation for its origin is a jökulhlaup (glacial outburst flood) induced by a temporary heat source under the ice due to a tectono-thermal or volcanic event (Clifford 1980a,b, 1987, 1993, Benito et al. 1997, Fishbaugh and Head 2002, Greve et al. 2004). Support for this mechanism is provided by 


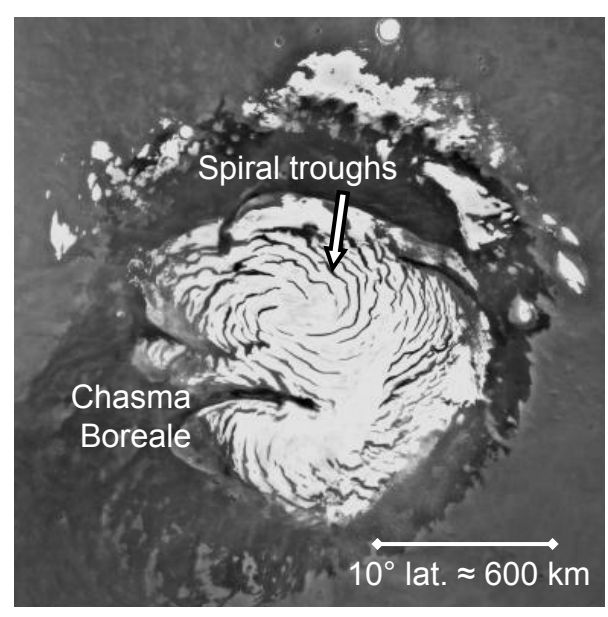

Figure 1: Martian north-polar cap with Chasma Boreale and the spiral troughs. Underlain Viking-1 Orbiter image: courtesy NASA/JPL-Caltech.

the likely identification of geologically young volcanic craterforms on the floor of Chasma Boreale and near its mouth (Hodges and Moore 1994, Garvin et al. 2000a,b, Sakimoto et al. 2000). Here, the possibility will be explored by assuming a locally increased geothermal heat flux in the region of Chasma Boreale for a limited period of time in the past, and simulating the dynamic/thermodynamic response of the ice cap with the model SICOPOLIS (SImulation COde for POLythermal Ice Sheets). The questions to be investigated are (i) how much geothermal heat over which amount of time is required to form the chasma, (ii) how much water is discharged by a process of that kind (catastrophic flooding?), (iii) what are the local ice-flow velocities at the slopes of the chasma, and (iv) which processes can keep the chasma open after the end of the heating event.

Alternative proposed mechanisms for chasmata formation in the Martian polar caps are katabatic wind erosion and differential ablation. The weakness of both possibilities is that they need an initial chasma as starting point in order to either channelize katabatic winds or provide an albedo contrast to the surrounding ice. Nevertheless, it is not the aim of this study to rule out either of these mechanisms, but to show the feasibility of the temporary heat source approach and to quantify the related processes for a range of possible scenarios.

\section{Modelling approach}

The ice-sheet model SICOPOLIS was developed in the mid-1990's for terrestrial ice sheets and successfully applied to problems of past, present and future glaciation of Greenland, Scandinavia/Eurasia, North America and Antarctica (e.g., Forsström and Greve 2004, Greve 1997, 2000, 2005, Greve et al. 1999, Savvin et al. 2000). Recent applications to the 
Martian NPC were carried out by Greve et al. (2004), Greve and Mahajan (2005). The model describes ice rheologically as an incompressible, heat-conducting power-law fluid with thermo-mechanical coupling due to the strong temperature dependence of the ice viscosity, and computes three-dimensionally the temporal evolution of ice extent, thickness, temperature, water content and age in response to external forcing. The latter is specified by (i) the mean annual air temperature above the ice (surface temperature), (ii) the surface mass balance (ice accumulation minus melting and evaporation), and (iii) the geothermal heat flux from below into the ice body.

Items (i) and (ii) constitute the climatic forcing and are provided by the Mars Atmosphere-Ice Coupler MAIC. The current version MAIC-1.5 (Greve 2006a) is driven directly by the orbital parameters obliquity, eccentricity and anomaly of vernal equinox (Laskar et al. 2004). Surface temperature is parameterized by the Local Insolation Temperature (LIT) scheme (B. Grieger, pers. comm. 2004), which uses a daily and latitude dependent radiation balance and includes a treatment of the seasonal $\mathrm{CO}_{2}$ cap. Surface mass balance is parameterized by an equilibrium-line approach in analogy to terrestrial glaciology (Greve et al. 2004, Greve and Mahajan 2005), with the present-day accumulation rate (of the order of $0.1 \mathrm{~mm} \mathrm{a}^{-1}$ ) as the main free parameter. As for item (iii), the geothermal heat flux, a standard value of $35 \mathrm{~mW} \mathrm{~m}^{-2}$ is chosen. The assumed thermal anomaly under Chasma Boreale is described by an increased heat flux, $q_{\mathrm{CB}}$, between $100 \mathrm{~mW} \mathrm{~m}^{-2}$ and $10 \mathrm{~W} \mathrm{~m}^{-2}$ for the entire chasma area. This distribution, rather than employing a single point source at the head of the chasma, can be justified by the existence of a field of putatively volcanic craterforms in the vicinity of the NPC which extends into Chasma Boreale (Sakimoto et al. 2000). The geothermal heat flux is imposed directly at the ice base (no thermal boundary layer in the underlying lithosphere considered), and any basal meltwater is assumed to be drained instantaneously.

The reaction of the Martian lithosphere on the temporally varying ice load is described by an elastic-lithosphere-relaxing-asthenosphere (ELRA) isostasy model with a lithospheric flexural stiffness of $K_{1}=3 \times 10^{25} \mathrm{Nm}$ and an isostatic time lag of $\tau_{\text {iso }}=3 \mathrm{ka}$ (Le Meur and Huybrechts 1996, Greve 2001). The value of the flexural stiffness has been chosen according to findings of the Mars Advanced Radar for Subsurface and Ionosphere Sounding (MARSIS) onboard the European Mars Express spacecraft. Bed reflections of the NPC indicate a small (if any) isostatic deflection of the lithosphere, corresponding to an elastic thickness of $\geq 150 \mathrm{~km}$ (Picardi et al. 2005). With the standard material parameters $E=$ $10^{11} \mathrm{~Pa}$ (Young's modulus) and $\nu=0.25$ (Poisson's ratio) (Johnson et al. 2000), $150 \mathrm{~km}$ yield the above-mentioned value of the flexural stiffness. Also, the small attenuation of the radar signals allows only clean ice with a maximum dust content of $2 \%$. Therefore, a temporally and spatially uniform dust content of $2 \%$ is assumed for the ice of the NPC in 
all simulations of this study. Ice flow is described by the standard Glen's flow law with stress exponent $n=3$ and activation energy $Q=60 \mathrm{~kJ} \mathrm{~mol}^{-1}$ (Greve 2006b). Numerical grid spacing in the horizontal plane is $10 \mathrm{~km}$, and time-steps between 10 and 1000 a are employed. Other physical parameters are listed in Table 1.

\begin{tabular}{ll}
\hline Quantity & Value \\
\hline Gravity acceleration, $g$ & $3.72 \mathrm{~m} \mathrm{~s}^{-2}$ \\
Density of ice, $\rho_{\mathrm{i}}$ & $910 \mathrm{~kg} \mathrm{~m}^{-3}$ \\
Melting point at atmospheric pressure, $T_{0}$ & $273.15 \mathrm{~K}$ \\
Heat conductivity of ice, $\kappa_{\mathrm{i}}$ & $9.828 e^{-0.0057 T[\mathrm{~K}]} \mathrm{W} \mathrm{m}^{-1} \mathrm{~K}^{-1}$ \\
Specific heat of ice, $c_{\mathrm{i}}$ & $(146.3+7.253 T[\mathrm{~K}]) \mathrm{J} \mathrm{kg}^{-1} \mathrm{~K}^{-1}$ \\
Latent heat of ice, $L$ & $335 \mathrm{~kJ} \mathrm{~kg}^{-1}$ \\
Clausius-Clapeyron gradient, $\beta$ & $3.3 \times 10^{-4} \mathrm{~K} \mathrm{~m}^{-1}$ \\
Density of crustal material, $\rho_{\mathrm{c}}$ & $2900 \mathrm{~kg} \mathrm{~m}^{-3}$ \\
Heat conductivity of crustal material, $\kappa_{\mathrm{c}}$ & $2.5 \mathrm{~W} \mathrm{~m}^{-1} \mathrm{~K}^{-1}$ \\
Specific heat of crustal material, $c_{\mathrm{c}}$ & $1000 \mathrm{~J} \mathrm{~kg}^{-1} \mathrm{~K}^{-1}$ \\
Flexural stiffness of the lithosphere, $K_{\mathrm{l}}$ & $3 \times 10^{25} \mathrm{~N} \mathrm{~m}$ \\
Isostatic time lag, $\tau_{\mathrm{iso}}$ & $3 \mathrm{ka}$ \\
Asthenosphere density, $\rho_{\mathrm{a}}$ & $3500 \mathrm{~kg} \mathrm{~m}^{-3}$ \\
\hline
\end{tabular}

Table 1: Standard physical parameters of the ice-sheet model SICOPOLIS.

\section{Reference simulation}

This simulation (run \#0) is driven by the orbital parameters provided by Laskar et al. (2004). Owing to the high obliquities prior to 5 Ma ago (Fig. 2) and correspondingly high summer evaporation rates, an ice-free initial state at $t=-5 \mathrm{Ma}$ is assumed, the simulation is run until the present $(t=0)$, and the accumulation rate is chosen such that the simulated present-day maximum surface elevation matches the observed value of $-1.95 \mathrm{~km}$ with respect to the reference geoid (Zuber et al. 1998, Smith et al. 1999). This tuning procedure yields a present-day accumulation rate of $0.23 \mathrm{~mm} \mathrm{a}^{-1}$. A thermal anomaly under Chasma Boreale is not assumed to arise, so that the geothermal heat flux is equal to $35 \mathrm{~mW} \mathrm{~m}^{-2}$ everywhere (see also Table 2 ).

The set-up is very similar to the reference simulation of Greve and Mahajan (2005). The ice volume increases monotonically over time, and the main 125-ka obliquity cycle is only reflected as a very small step-like modification in the curve (Fig. 3). Hence, the NPC topography responds mainly to the long-term average climate conditions. The result for the present is an almost circularly symmetric ice cap centered at the north pole with an area of $0.993 \times 10^{6} \mathrm{~km}^{2}$ and a volume of $1.4265 \times 10^{6} \mathrm{~km}^{3}$ (Fig. 3). Thus, the overall shape of the ice cap is modelled well, whereas medium- and small-scale structures like Chasma Boreale 


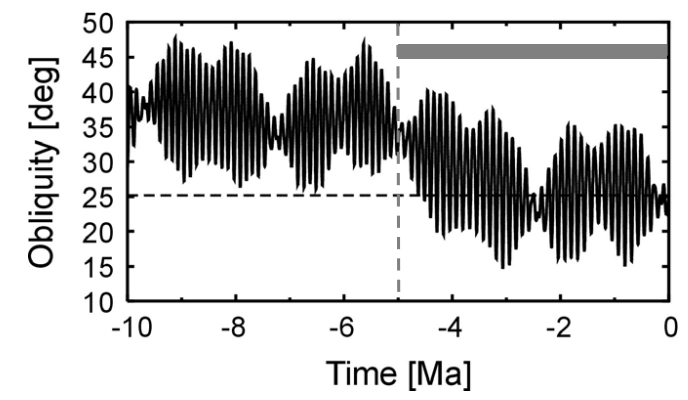

Figure 2: Martian obliquity for the last $10 \mathrm{Ma}$ (Laskar et al. 2004). The grey bar indicates the most recent 5-Ma period with relatively low average obliquity, during which the NPC is assumed to have formed.
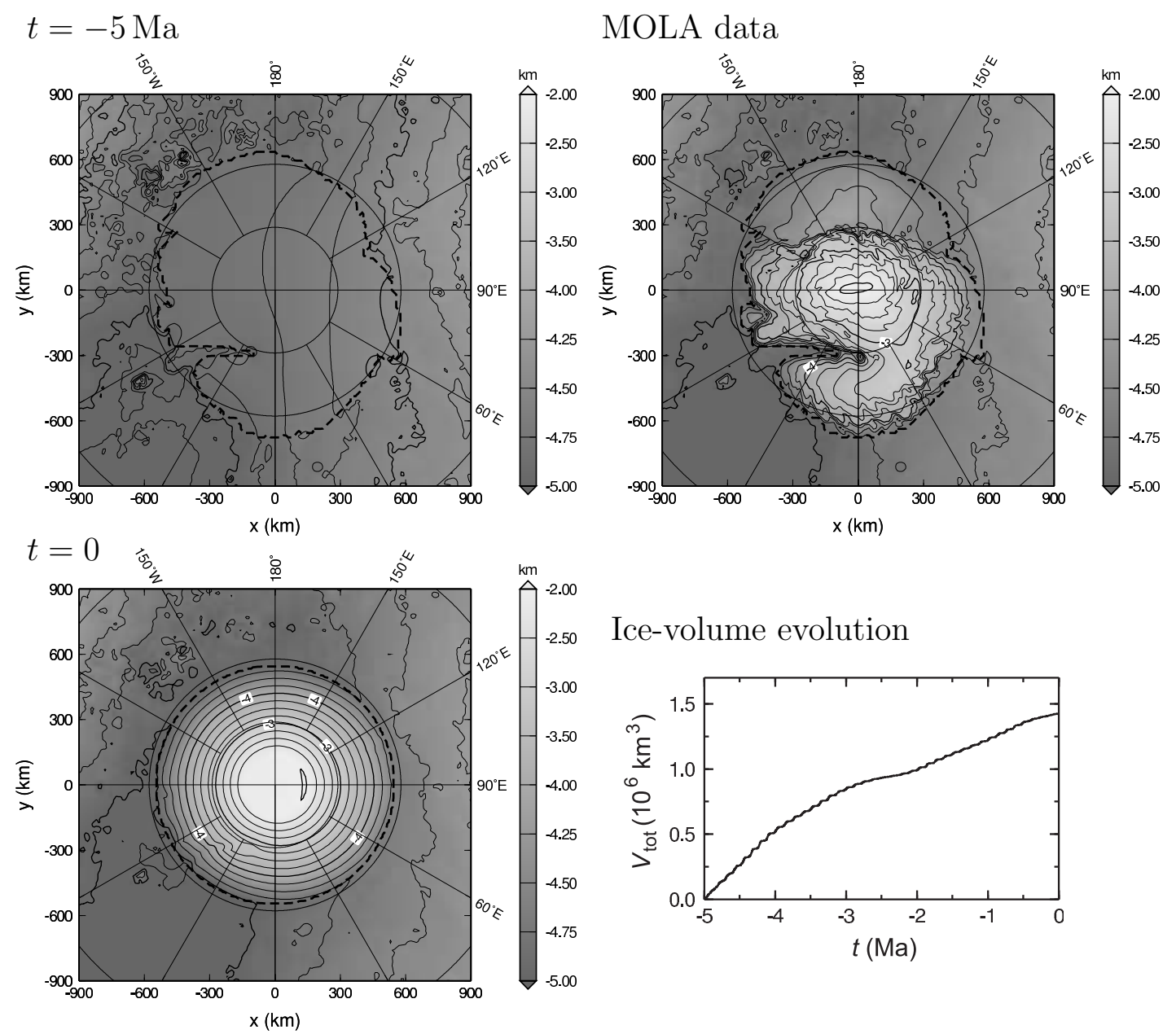

Ice-volume evolution

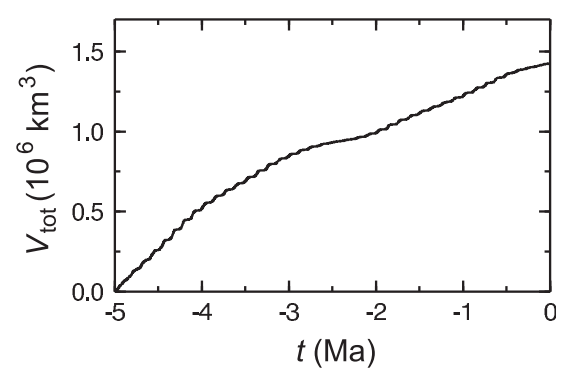

Figure 3: Reference simulation (run \#0): Surface topography for $t=-5 \mathrm{Ma}$ (initial state) and $t=0$ (present), observed MOLA topography for comparison (in $\mathrm{km}$ relative to the reference geoid). Also shown is the ice-volume evolution during this period.

and the spiralling pattern of surface troughs are not reproduced. The slight dents in the elevation contours at the location of Chasma Boreale are a consequence of the equilibrated 
ground topography, which has been constructed by a smooth extrapolation of the ice-free ground surrounding the NPC and shows a small depression in the chasma region (Greve et al. 2004). The maximum basal temperature (relative to the pressure melting point) is $T_{\mathrm{b}, \max }^{\prime}=-74.90^{\circ} \mathrm{C}$, and the maximum surface velocity is $v_{\mathrm{s}, \max }=0.26 \mathrm{~mm} \mathrm{a}^{-1}$. Therefore, the simulated ice cap is very cold throughout its volume, and it features very slow glacial flow, which is four to five orders of magnitude slower than typical values for terrestrial ice sheets.

\section{Simulations with thermal anomaly}

In addition to the set-up of the reference simulation, a thermal anomaly (increased heat flux, $\left.q_{\mathrm{CB}}\right)$ is now assumed to arise under the entire area of Chasma Boreale. Since no information about the strength and cycle of such an anomaly is available, a variety of different scenarios will be run through. An overview is given in Table 2.

\subsection{Thermal anomaly always active}

Runs \#1-5 have been carried out with $q_{\mathrm{CB}}=100,150,200,500 \mathrm{~mW} \mathrm{~m}^{-2}$ and $1 \mathrm{~W} \mathrm{~m}^{-2}$, respectively, active throughout the simulation time of $5 \mathrm{Ma}$. For runs \#1 and 2, the basal temperature does not reach the melting point $\left(T_{\mathrm{b}, \max }^{\prime}=-45.01^{\circ} \mathrm{C}\right.$ and $-5.26^{\circ} \mathrm{C}$, respectively), and the surface velocity in the chasma region increases only slightly $\left(v_{\mathrm{s}, \max }=\right.$ $0.45 \mathrm{~mm} \mathrm{a}^{-1}$ and $4.82 \mathrm{~mm} \mathrm{a}^{-1}$, respectively). For runs \#3-5, the basal temperature in the chasma region is at the melting point, and $v_{\mathrm{s}, \max }$ reaches values between 10 and $20 \mathrm{~mm} \mathrm{a}^{-1}$. Run \#3 only produces a small topographic depression, whereas runs \#4 and 5 produce a depression similar to the real chasma (Fig. 4). Therefore, a thermal anomaly with a heat flux of $\geq 500 \mathrm{~mW} \mathrm{~m}^{-2}$ is required to form a topographic depression similar to Chasma Boreale. The residual ice thickness in the depression is between 600 and $700 \mathrm{~m}$ for run \#4, and between 300 and $400 \mathrm{~m}$ for run \#5.

The distorting effect of the forming depression on the surface topography of the rest of the ice cap is limited to the immediate vicinity of the depression. Further away, the ice cap builds up essentially undisturbed, and the present-day elevation contours to the south-east of the depression are in direct continuation of the contours to the north-west. Evidently, the accelerated glacial flow along the walls of the depression limits the slope of the walls, but it not sufficiently pronounced to have a farther-reaching effect.

The bottom panel of Fig. 4 shows the present-day surface velocity for run \#5. It is not surprising that enhanced values (between 1 and $10 \mathrm{~mm} \mathrm{a}^{-1}$ ) occur around the chasma walls, where surface slopes are largest, whereas everywhere else glacial flow is very slow. 

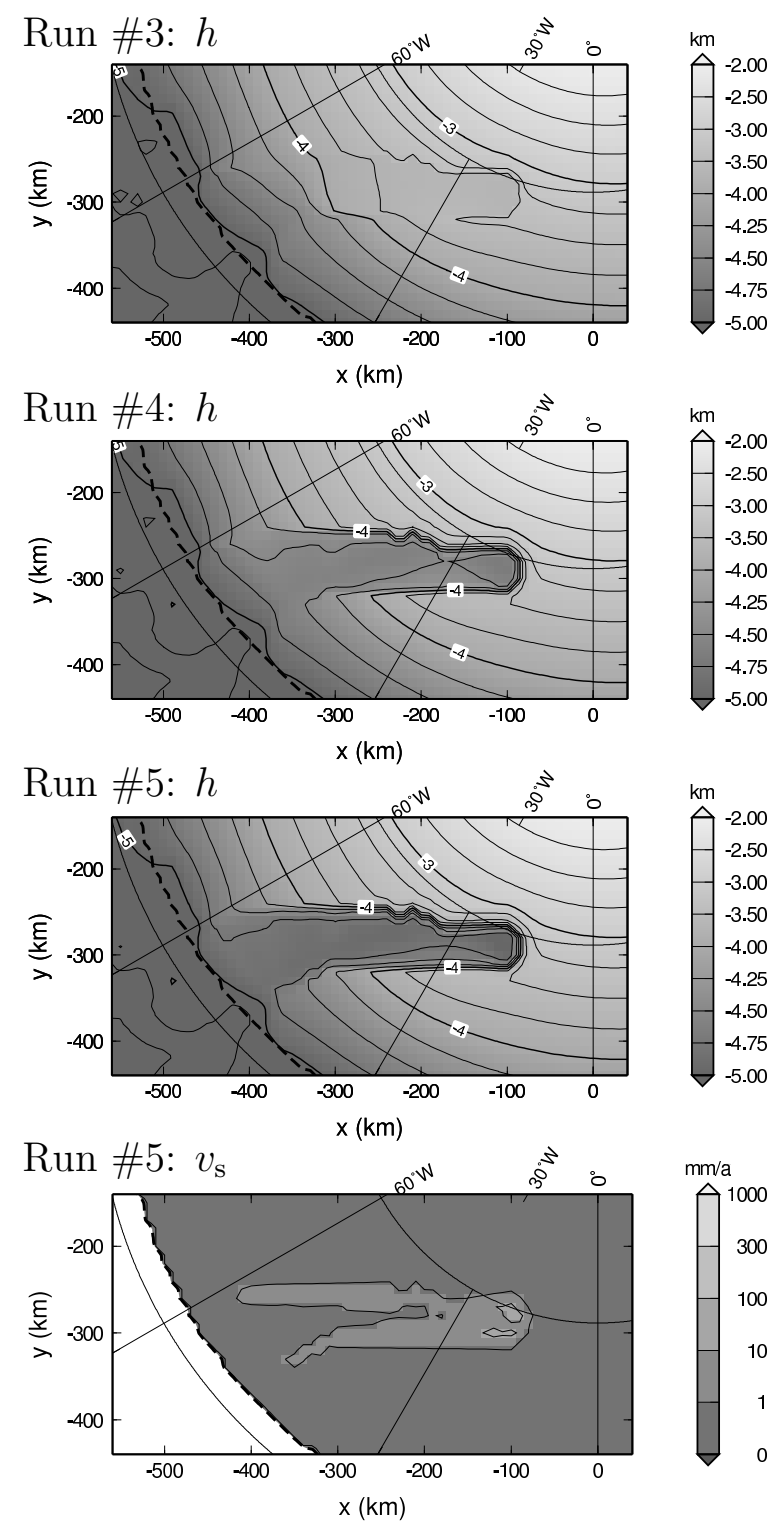

Figure 4: Runs \#3, 4, 5: Surface topography $h$ and surface velocity $v_{\mathrm{s}}$ at the present $(t=0)$ in the vicinity of Chasma Boreale.

The highest velocities $\left(>10 \mathrm{~mm} \mathrm{a}^{-1}\right)$ are found at the head of the chasma.

Figure 5 depicts the evolution of the maximum basal temperature $T_{\mathrm{b} \text {,max }}^{\prime}$, the basal melting rate (meltwater discharge) $Q$ and the maximum surface velocity $v_{\mathrm{s}, \max }$ for run \#5 over the entire simulation time. All quantities reflect the 125-ka obliquity cycle as well as its 1.3-Ma modulation, the basal temperature being at the pressure melting point essentially always throughout the most recent $1.5 \mathrm{Ma}$. The basal melting rate (meltwater discharge) is very small, with peak values of only $\approx 0.03 \mathrm{~km}^{3} \mathrm{a}^{-1}$, which constitutes mild seepage rather than significant flooding events. The maximum present-day surface velocity of $20.3 \mathrm{~mm} \mathrm{a}^{-1}$ is surpassed by a value of $46.6 \mathrm{~mm} \mathrm{a}^{-1}$ which occurs 800 ka ago, shortly 

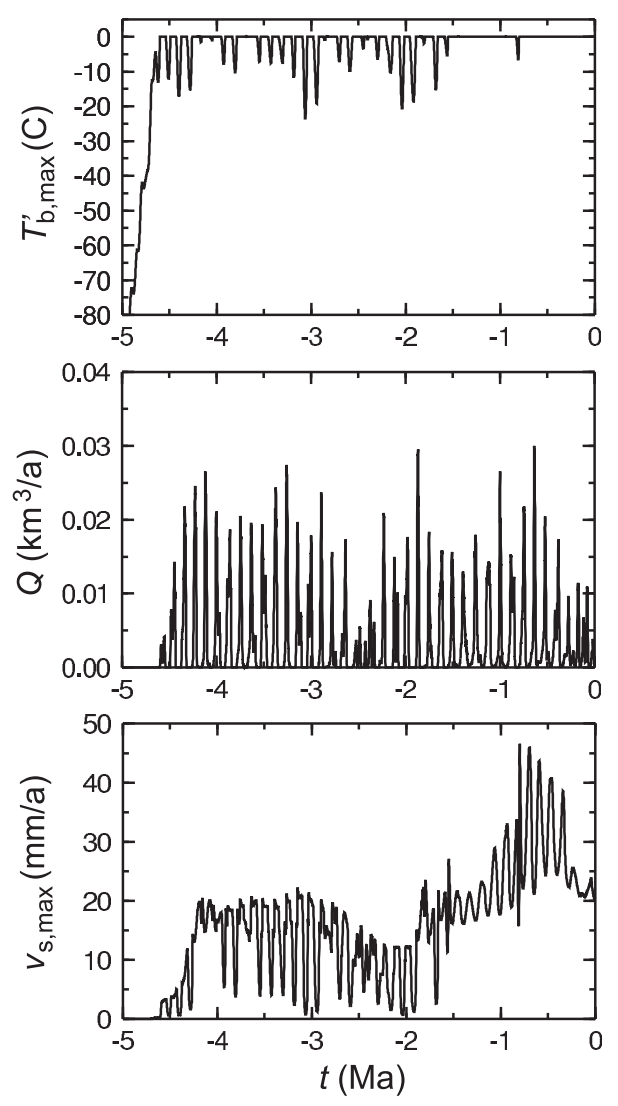

Figure 5: Run \#5: Evolution of the maximum basal temperature $T_{\mathrm{b}, \max }^{\prime}$, the basal melting rate (meltwater discharge) $Q$ and the maximum surface velocity $v_{\mathrm{s}, \max }$.

after the maximum basal temperature fell below the pressure melting point for the last time.

\subsection{Thermal anomaly temporarily active}

It is now assumed that the thermal anomaly was only active during a limited period in the past. For run $\# 6, q_{\mathrm{CB}}=1 \mathrm{~W} \mathrm{~m}^{-2}$, active during the last $100 \mathrm{ka}$, and for run $\# 7$, $q_{\mathrm{CB}}=10 \mathrm{~W} \mathrm{~m}^{-2}$, active during the last $10 \mathrm{ka}$.

In both cases, the basal temperature jumps to the pressure melting point very rapidly after the activation of the thermal anomaly, and from then on the chasma forms (Fig. 6). For run \#6, the pressure melting point is reached after 800 a, followed 200 a later by a sharp peak of the maximum surface velocity at a value of $0.61 \mathrm{ma}^{-1}$. The basal melting rate (meltwater discharge) is maximal 4400 a after the activation of the anomaly at a value of $0.64 \mathrm{~km}^{3} \mathrm{a}^{-1}$. This is an order of magnitude more than in run \#5, but still relatively moderate. For run \#7, the basal temperature jumps to the pressure melting point within a single numerical time-step of 10 a. The basal melting rate (meltwater discharge) peaks 
140 a after the activation of the anomaly at a value of $11.45 \mathrm{~km}^{3} \mathrm{a}^{-1}$, now comparable to a minor jökulhlaup on Earth. The maximum surface velocity takes its maximum 1640 a after the activation of the anomaly, at a remarkable value of $2.23 \mathrm{~m} \mathrm{a}^{-1}$. For the present, both runs produce a fully developed chasma similar to that of run \#5 shown in Fig. 4, and the flow velocities have fallen again to very small values. The residual ice thickness in the chasma is between 300 and $400 \mathrm{~m}$ for run \#6, and between 30 and $40 \mathrm{~m}$ for run \#7.
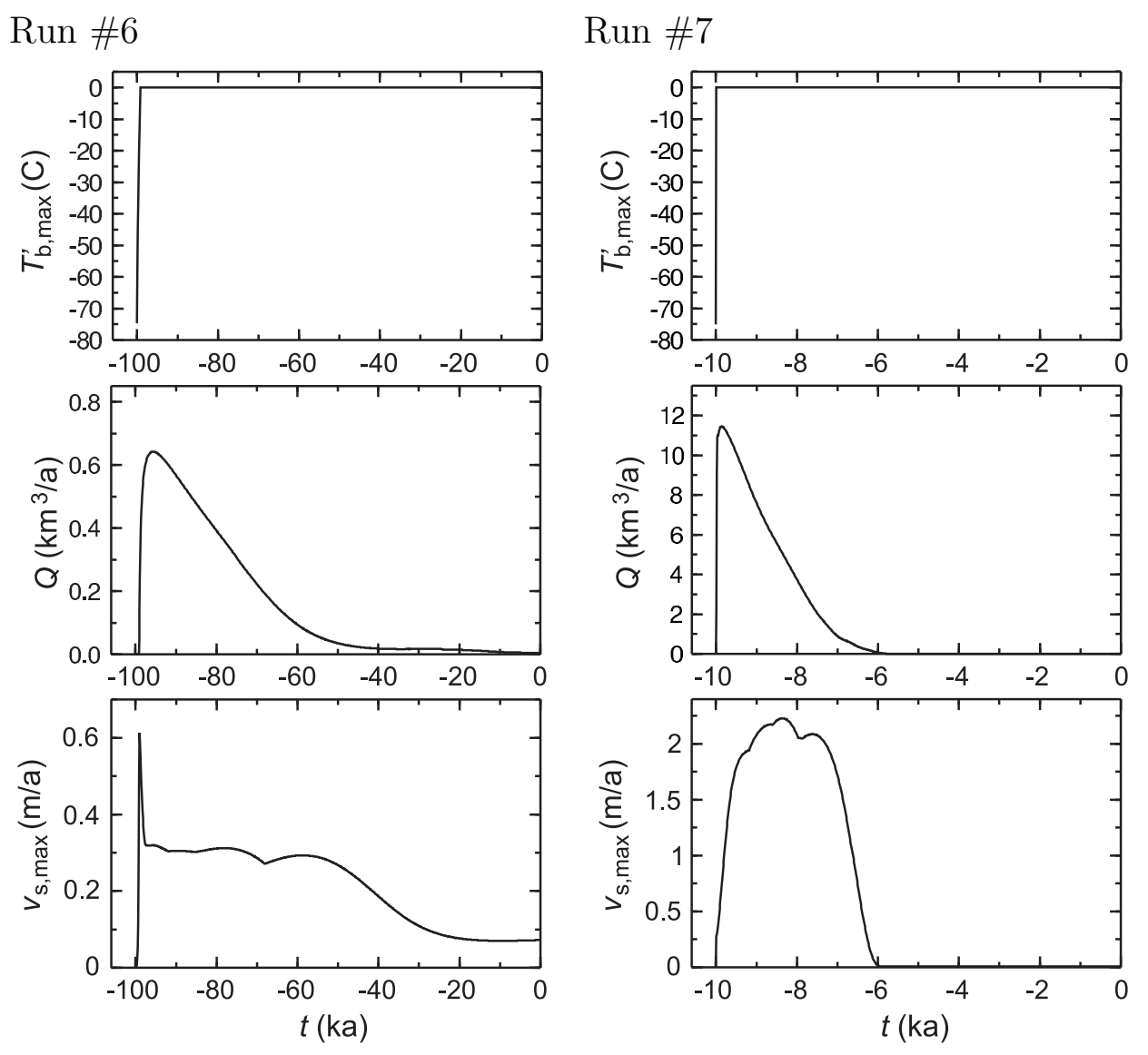

Figure 6: Runs \#6, 7: Evolution of the maximum basal temperature $T_{\mathrm{b}, \max }^{\prime}$, the basal melting rate (meltwater discharge) $Q$ and the maximum surface velocity $v_{\mathrm{s}, \max }$ during the period when the thermal anomaly is active.

A sequence of surface topographies and velocities for run \#7 is shown in Fig. 7. Starting from the undisturbed surface at $t=-10 \mathrm{ka}$, the formation of the topographic depression proceeds rapidly, which goes along with fast glacial flow $\left(>1 \mathrm{~m} \mathrm{a}^{-1}\right)$ at the head and along the walls of the chasma. At $t=-6 \mathrm{ka}$, the depression is essentially fully developed, and from then on, not much happens any more. Between $5.96 \mathrm{ka}$ ago and the present, velocities larger than $10 \mathrm{~mm} \mathrm{a}^{-1}$ do not occur any more, and during the last 5.8 ka the meltwater discharge is always less than $0.01 \mathrm{~km}^{3} \mathrm{a}^{-1}$. 

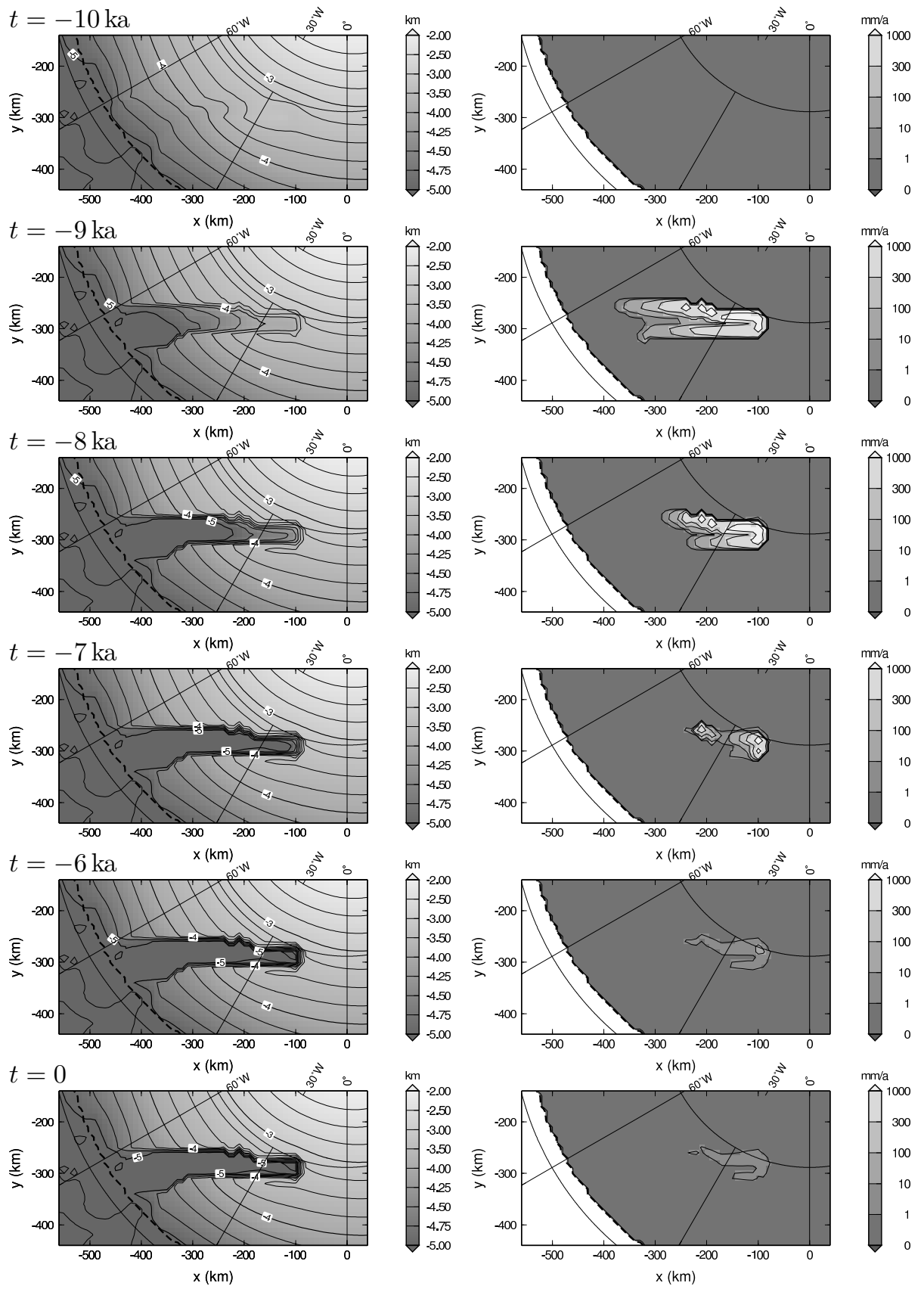

Figure 7: Run \#7: Sequence of simulated surface topographies (left) and surface velocities (right) in the vicinity of Chasma Boreale.

\subsection{Chasma closure}

So far, it was assumed in all simulations that the thermal anomaly is active until the present. However, this assumption is not supported by any observations, and it is equally possible that the thermal anomaly has died out at some time in the past. The question arises how long the chasma can exist without an ongoing process to keep it open.

Run \#8 focuses on this problem. Like for run \#6, the enhanced heat flux of the thermal 
anomaly is $q_{\mathrm{CB}}=1 \mathrm{~W} \mathrm{~m}^{-2}$, but the active period is now between $t=-500 \mathrm{ka}$ and $-400 \mathrm{ka}$. Figure 8 compares the surface topographies at $t=-400 \mathrm{ka}$ and $t=0$. It is evident that no significant chasma closure occurs during these $400 \mathrm{ka}$, even though the thermal anomaly is inactive and no process supports the further existence of the chasma.

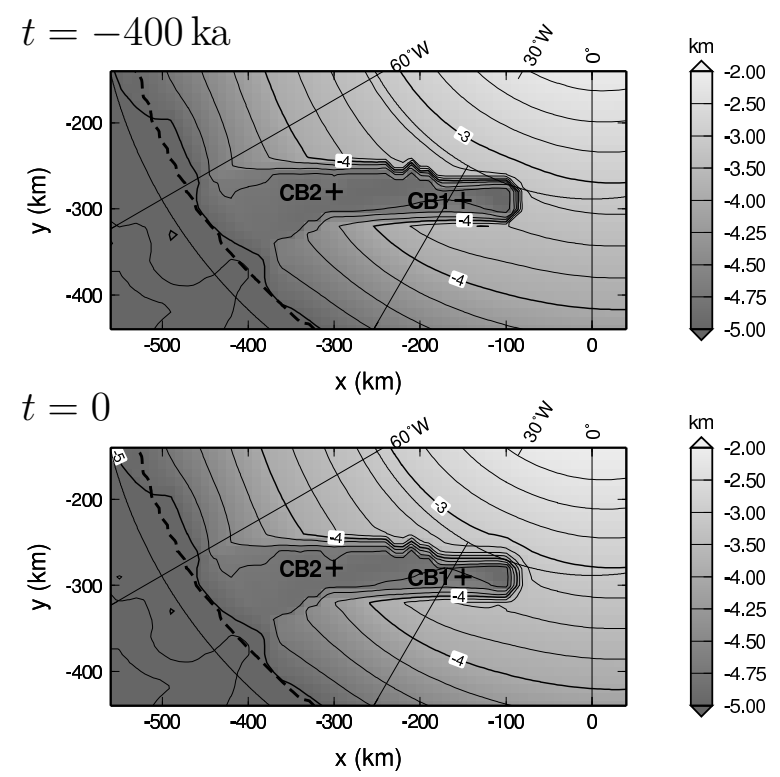

Figure 8: Run \#8: Simulated surface topographies at $t=-400$ ka (thermal anomaly switched off) and $t=0$ (present) in the vicinity of Chasma Boreale. Two positions "CB1" and "CB2" in the chasma are marked.

This behaviour becomes understandable by inspection of Fig. 9, which shows the maximum basal temperature, maximum surface velocity and ice thickness at two selected points in the chasma. As expected, during the active period, the results are very similar to those of run \#6 (see Fig. 6 for comparison). After the shutdown of the thermal anomaly at $t=-400 \mathrm{ka}$, the state of the ice cap returns rapidly to "normal" conditions, similar to those of the reference simulation discussed above (run \#0). Only 200 a after the shutdown, the maximum basal temperature has dropped from the pressure melting point to about $-75^{\circ} \mathrm{C}$. This makes the ice so stiff that glacial flow slows down to a few millimeters per year even at the steep chasma walls. It is clear that these small velocities do not allow any significant closure of the chasma. Consequently, the ice thickness at the points CB1 and CB2 in the chasma (see Fig. 8) increases only very slowly, at average rates of $0.169 \mathrm{~mm} \mathrm{a}^{-1}$ (CB1) and $0.106 \mathrm{~mm} \mathrm{a}^{-1}$ (CB2) over the $400 \mathrm{ka}$. Even this slow thickening is mainly due to the positive surface mass balance provided by the Mars Atmosphere-Ice Coupler MAIC, and not due to glacial flow itself.

In order to investigate the closure behaviour of the chasma due to glacial flow only on very long time-scales, run \#9 has been devised as a continuation of run \#6 for 10 Ma into 

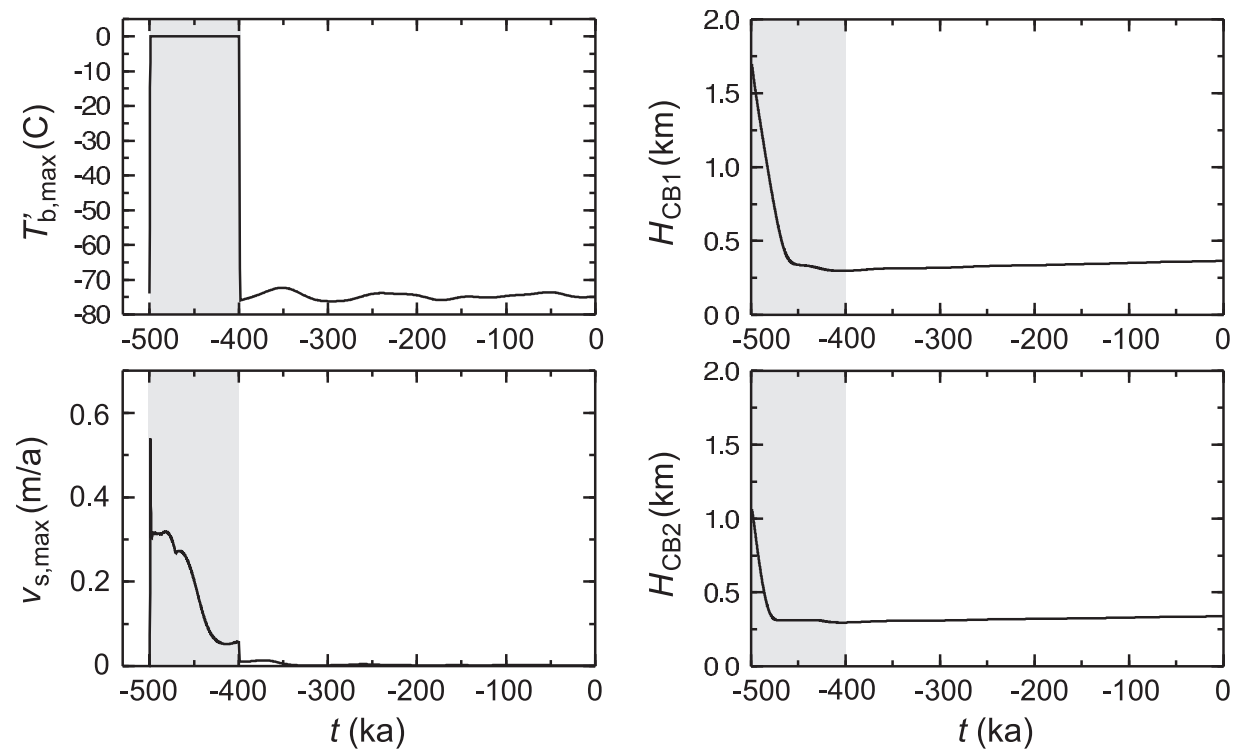

Figure 9: Run \#8: Evolution of the maximum basal temperature $T_{\mathrm{b}, \max }^{\prime}$, the maximum surface velocity $v_{\mathrm{s}, \max }$ and the ice thicknesses $H$ at the positions CB1 and CB2 (see Fig. 8) during and after the period when the thermal anomaly is active. Light-grey shading indicates the 100-ka active period.

the future, with inactive thermal anomaly and zero surface mass balance assumed. Like in run \#8, basal temperatures and flow velocities drop rapidly to very low values despite the presence of the chasma (results not shown). Chasma closure over the entire model time of $10 \mathrm{Ma}$ is entirely negligible, the thickening at CB1 being merely $50 \mathrm{~mm}$ and at CB2 even less than $10 \mathrm{~mm}$. These results effectively rule out glacial flow as a closure mechanism for Chasma Boreale after the shutdown of the thermal anomaly. 


\begin{tabular}{ccccc}
\hline Run & Model time & $\begin{array}{c}\text { Thermal anomaly } \\
\text { active }\end{array}$ & $q_{\mathrm{CB}}$ & Remarks \\
\hline$\# 0$ & $-5 \mathrm{Ma} \ldots 0$ & never & - & Reference run \\
$\# 1$ & $-5 \mathrm{Ma} \ldots 0$ & always & $100 \mathrm{~mW} \mathrm{~m}^{-2}$ & - \\
$\# 2$ & $-5 \mathrm{Ma} \ldots 0$ & always & $150 \mathrm{~mW} \mathrm{~m}^{-2}$ & - \\
$\# 3$ & $-5 \mathrm{Ma} \ldots 0$ & always & $200 \mathrm{~mW} \mathrm{~m}^{-2}$ & - \\
$\# 4$ & $-5 \mathrm{Ma} \ldots 0$ & always & $500 \mathrm{~mW} \mathrm{~m}^{-2}$ & - \\
$\# 5$ & $-5 \mathrm{Ma} \ldots 0$ & always & $1 \mathrm{~W} \mathrm{~m}^{-2}$ & - \\
$\# 6$ & $-5 \mathrm{Ma} \ldots 0$ & $-100 \mathrm{ka} \ldots 0$ & $1 \mathrm{~W} \mathrm{~m}^{-2}$ & - \\
$\# 7$ & $-5 \mathrm{Ma} \ldots 0$ & $-10 \mathrm{ka} \ldots 0$ & $10 \mathrm{~W} \mathrm{~m}^{-2}$ & - \\
$\# 8$ & $-5 \mathrm{Ma} \ldots 0$ & -500 ka ... $.400 \mathrm{ka}$ & $1 \mathrm{~W} \mathrm{~m}^{-2}$ & - \\
$\# 9$ & $0 \ldots 10 \mathrm{Ma}$ & never & - & Zero surface \\
& & & & mass balance \\
\hline
\end{tabular}

Table 2: Set-up of the ten different simulations. 


\section{Discussion and conclusion}

The simulations discussed in this study have identified a temporary heat source (due to a tectono-thermal or volcanic event) under the ice of the NPC as a plausible mechanism for the formation of Chasma Boreale. A moderately increased heat flux of $0.5-1 \mathrm{~W} \mathrm{~m}^{-2}$, sustained over at least tens of thousands of years, is sufficient to produce a topographic depression which resembles the real chasma. The associated meltwater discharge rates depend on the timing of the activity of the thermal anomaly, but are in any case less than $1 \mathrm{~km}^{3} \mathrm{a}^{-1}$. A strongly increased heat flux of $10 \mathrm{~W} \mathrm{~m}^{-2}$ (which is still well below possible heat fluxes on Earth during an active volcanic eruption, though) does the job within a few thousand years and generates peak discharge rates of $>10 \mathrm{~km}^{3} \mathrm{a}^{-1}$, which is comparable to a minor jökulhlaup (glacial flood) on Earth.

Local ice-flow velocities during the process of chasma formation can exceed $1 \mathrm{~m} \mathrm{a}^{-1}$ at the head and scarps of the chasma. However, after the topographic depression has formed completely, glacial flow quickly slows down even if the thermal anomaly remains active, and even more so if the anomaly shuts down. Therefore, chasma closure due to glacial flow is not an issue. Under the climatic conditions of the recent millions of years, the chasma can stay open for an indefinite amount of time without an ongoing, sustaining process of any kind, unless it is filled by ice accumulation.

Some limitations of this study must be noted. The applied modelling is a large-scale approach based on the shallow ice approximation (Hutter 1983, Morland 1984) and a grid spacing in the horizontal plane of $10 \mathrm{~km}$. While this is sufficient to resolve Chasma Boreale as a whole reasonably well, the maximum value of the discretized slope of the chasma walls is $\approx 2 \mathrm{~km} / 10 \mathrm{~km}=0.2$ (where $2 \mathrm{~km}$ is the maximum height of the walls). This is to say that steep scarps are not resolvable, and the shallow ice approximation is not valid under such conditions anyway. Therefore, local flow processes in the immediate vicinity of steep scarps cannot be modelled adequately.

Further, let us recall the assumption that any basal meltwater produced by the increased heat flux under Chasma Boreale is drained instantaneously. Since this depends on the detailed hydraulic conditions at the ice base about which virtually nothing is known, it is very difficult to judge how realistic this assumption is. Alternatively, the basal meltwater may be stored under the ice for a certain amount of time and then be released in a catastrophic outburst flood, similar to a large terrestrial jökulhlaup with discharge rates orders of magnitude larger than those found here under the assumption of instantaneous meltwater drainage. 


\section{Acknowledgements}

The author wishes to thank Dr. Björn Grieger and Dr. Oliver Stenzel (Max Planck Institute for Solar System Research, Katlenburg-Lindau, Germany) for their cooperation with the Mars Atmosphere-Ice Coupler MAIC. Thanks are extended to the two referees of the paper, Dr. Thorsteinn Thorsteinsson (Icelandic National Energy Authority, Reykjavík, Iceland) and Dr. Christine Schøtt Hvidberg (University of Copenhagen, Denmark), and the scientific editor, Dr. Peter C. Thomas (Cornell University, Ithaca, New York, USA), for helpful comments.

This study was carried out as part of the project "Evolution and dynamics of the Martian polar ice caps over climatic cycles", supported by the Research Fund of the Institute of Low Temperature Science, Sapporo, Japan.

\section{References}

Benito, G., F. Mediavilla, M. Fernández, A. Márquez, J. Martínez and F. Anguita. 1997. Chasma Boreale, Mars: a sapping and outflow channel with a tectono-thermal origin. Icarus, 129 (2), $528-538$.

Byrne, S. and B. C. Murray. 2002. North polar stratigraphy and the paleo-erg of Mars. J. Geophys. Res., 107 (E6), 5044. doi:10.1029/2001JE001615.

Clifford, S. M. 1980a. Chasma Boreale $\left(85^{\circ} \mathrm{N}, 0^{\circ} \mathrm{W}\right)$ : Remnant of a Martian jökulhlaup? Bull. Am. Astron. Soc., 12, 678-679.

Clifford, S. M. 1980b. Mars: Polar cap basal melting as a recharge mechanism for a global groundwater system. In: 11th Lunar and Planetary Science Conference, pp. 165-167. Lunar and Planetary Institute, Houston, Texas, USA.

Clifford, S. M. 1987. Polar basal melting on Mars. J. Geophys. Res., 92 (B9), 9135-9152.

Clifford, S. M. 1993. A model for the hydrologic and climatic behavior of water on Mars. J. Geophys. Res., 98 (E6), 10973-11016.

Fishbaugh, K. E. and J. W. Head. 2002. Chasma Boreale, Mars: Topographic characterization from Mars Orbiter Laser Altimeter data and implications for mechanisms of formation. $J$. Geophys. Res., 107 (E3), 5013. doi:10.1029/2000JE001351.

Forsström, P.-L. and R. Greve. 2004. Simulation of the Eurasian ice sheet dynamics during the last glaciation. Global Planet. Change, 42 (1-4), 59-81. doi:10.1016/j.gloplacha.2003.11.003. 
Garvin, J. B., S. E. H. Sakimoto, J. J. Frawley and C. C. Schnetzler. 2000a. North polar region craterforms on Mars: Geometric characteristics from the Mars Orbiter Laser Altimeter. Icarus, $144(2), 329-352$.

Garvin, J. B., S. E. H. Sakimoto, J. J. Frawley, C. C. Schnetzler and H. M. Wright. 2000b. Topographic evidence for geologically recent near-polar volcanism on Mars. Icarus, 145 (2), 648-652.

Greve, R. 1997. Application of a polythermal three-dimensional ice sheet model to the Greenland ice sheet: Response to steady-state and transient climate scenarios. J. Climate, 10 (5), 901918.

Greve, R. 2000. On the response of the Greenland ice sheet to greenhouse climate change. Climatic Change, 46 (3), 289-303.

Greve, R. 2001. Glacial isostasy: Models for the response of the Earth to varying ice loads. In: B. Straughan, R. Greve, H. Ehrentraut and Y. Wang (Eds.), Continuum Mechanics and Applications in Geophysics and the Environment, pp. 307-325. Springer, Berlin etc.

Greve, R. 2005. Relation of measured basal temperatures and the spatial distribution of the geothermal heat flux for the Greenland ice sheet. Ann. Glaciol., 42, 424-432.

Greve, R. 2006a. Evolution and dynamics of the Martian polar ice caps over climatic cycles. In: ILTS Research Fund, Report, May 2006, pp. 43-47. Institute of Low Temperature Science (ILTS), Hokkaido University, Sapporo, Japan.

Greve, R. 2006b. Fluid dynamics of planetary ices. GAMM-Mitt., 29 (1), 29-51.

Greve, R. and R. A. Mahajan. 2005. Influence of ice rheology and dust content on the dynamics of the north-polar cap of Mars. Icarus, 174 (2), 475-485. doi:10.1016/j.icarus.2004.07.031.

Greve, R., R. A. Mahajan, J. Segschneider and B. Grieger. 2004. Evolution of the north-polar cap of Mars: a modelling study. Planet. Space Sci., 52 (9), 775-787. doi:10.1016/j.pss.2004.03.007.

Greve, R., K.-H. Wyrwoll and A. Eisenhauer. 1999. Deglaciation of the Northern Hemisphere at the onset of the Eemian and Holocene. Ann. Glaciol., 28, 1-8.

Hodges, C. A. and H. J. Moore. 1994. Atlas of Volcanic Landforms on Mars. USGS Professional Paper No. 1534. U.S. Government Printing Office, Washington, DC.

Hutter, K. 1983. Theoretical Glaciology; Material Science of Ice and the Mechanics of Glaciers and Ice Sheets. D. Reidel Publishing Company, Dordrecht, The Netherlands.

Johnson, C. L., S. C. Solomon, J. W. Head, R. J. Phillips, D. E. Smith and M. T. Zuber. 2000. Lithospheric loading by the northern polar cap on Mars. Icarus, 144 (2), 313-328. 
Laskar, J., A. C. M. Correia, M. Gastineau, F. Joutel, B. Levrard and P. Robutel. 2004. Long term evolution and chaotic diffusion of the insolation quantities of Mars. Icarus, 170 (2), 343-364. doi:10.1016/j.icarus.2004.04.005.

Le Meur, E. and P. Huybrechts. 1996. A comparison of different ways of dealing with isostasy: examples from modelling the Antarctic ice sheet during the last glacial cycle. Ann. Glaciol., 23, 309-317.

Morland, L. W. 1984. Thermo-mechanical balances of ice sheet flows. Geophys. Astrophys. Fluid Dyn., 29, 237-266.

Picardi, G., J. J. Plaut, D. Biccari, O. Bombaci, D. Calabrese, M. Cartacci, A. Cicchetti, S. M. Clifford, P. Edenhofer, W. M. Farrell, C. Federico, A. Frigeri, D. A. Gurnett, T. Hagfors, E. Heggy, A. Herique, R. L. Huff, A. B. Ivanov, W. T. K. Johnson, R. L. Jordan, D. L. Kirchner, W. Kofman, C. J. Leuschen, E. Nielsen, R. Orosei, E. Pettinelli, R. J. Phillips, D. Plettemeier, A. Safaeinili, R. Seu, E. R. Stofan, G. Vannaroni, T. R. Watters and E. Zampolini. 2005. Radar soundings of the subsurface of Mars. Science, 310 (5756), 1925-1928. doi:10.1126/science.1122165.

Sakimoto, S. E. H., J. B. Garvin, M. Wong and H. Wright. 2000. Topography of small volcanoes at the margin of the Mars north polar cap. In: Second International Conference on Mars Polar Science and Exploration, LPI Contribution No. 1057, pp. 152-153. Lunar and Planetary Institute, Houston, Texas, USA.

Savvin, A. A., R. Greve, R. Calov, B. Mügge and K. Hutter. 2000. Simulation of the Antarctic ice sheet with a three-dimensional polythermal ice-sheet model, in support of the EPICA project. II. Nested high-resolution treatment of Dronning Maud Land, Antarctica. Ann. Glaciol., 30, $69-75$.

Smith, D. E., M. T. Zuber, S. C. Solomon, R. J. Phillips, J. W. Head, J. B. Garvin, W. B. Banerdt, D. O. Muhleman, G. H. Pettengill, G. A. Neumann, F. G. Lemoine, J. B. Abshire, O. Aharonson, C. D. Brown, S. A. Hauck, A. B. Ivanov, P. J. McGovern, H. J. Zwally and T. C. Duxbury. 1999. The global topography of Mars and implications for surface evolution. Science, 284 (5419), 1495-1503.

Zuber, M. T., D. E. Smith, S. C. Solomon, J. B. Abshire, R. S. Afzal, O. Aharonson, K. Fishbaugh, P. G. Ford, H. V. Frey, J. B. Garvin, J. W. Head, A. B. Ivanov, C. L. Johnson, D. O. Muhleman, G. A. Neumann, G. H. Pettengill, R. J. Phillips, X. Sun, H. J. Zwally, W. B. Banerdt and T. C. Duxbury. 1998. Observations of the north polar region of Mars from the Mars Orbiter Laser Altimeter. Science, 282 (5396), 2053-2060. 